\title{
Macintosh decoder and retrieval program for the international igneous rock data base IGBA
}

The international tgneous rock data base, which currently contains petrographical and geochemical data on about 15,000 igneous rocks, has been available to users to manage and query through specialized sets of FORTRAN subroutines. Now it is possible to use the data base through a user-friendly, stand alone (run-time) program that decodes and retrieves from the data base and that can be used almost immediately by anyone who has a Macintosh. (Ed:)

\section{Introduction}

The international igneous rock data base (1GBA) has been developed under the aegis of two successive IGCP projects ( 169 and 239 ) and under the IUGS Subcommission on Datat Bases for Ppetrology. A working data base was designed and then developed that currently comtains petrographical and genchemical data on about 15,000 igneous rocks, worldwide. At present, magnetic tapes of the IGBA atre avitiable at nominal cost to anyone whe applies to World Data Center-A (Colurado), or free of thatge to all who contribute analyses directly to the data base. The history of the IGBA (and of petrolngical data bases in general) and detals of its practice and implenenlation have been amply described hy Chayes (1983,1987, and 1990), by L.e Maitre (1982), and - in a broader review of computing developtments in petrology and mincralogy - by Rock (1991).

The IGBA was a pioneer in its class. and it indecd still carries some marks of its conception in the carly 1970 s and gestation in the decade that followed -- a time when computing was regularly pratticed on mainframes by relatively few geologists because of the inaccessibility, cost. and inapproachability of these machines and their software. For extmple, the data-base management systems (DBMSs available al the time were few, very costly, and prohibitively difficult to use, which led to the develspment of specialized sets of FORTRAN subroutines rogether with BASIC versions

\begin{abstract}
thereof) for the managing and querying of the IGBA (Chayes. 1983 : These subroutines still represent the only software currently released with the data base on tape. and they present some difficulties to user without FORTRAN expertise. Again. storage costs at the time meant that compactness was a major aim. and considerahle effort wa therefore put into the development of an elaborately coded, ultrit. condensed data-format (see fig. $x$ ). Althouph it was never intended that ultimate users would have to master this. It does nowidaly appear. somewhat impenetrable and mas unfortunately discouraly. some of today' potential users. who may perhaps be more whed " natural (English-like) computer interfaces; in any case, it requiro complete decoding for prictical use.

Data hases developed in the microcomputer cra have faces different, but on the whole. lesser problems: developers have hat available a wealth of versatile DBMSs that can he henght off th: shelf at relatively litcle cost. compared to their mainframe forehear (for example, dBase, FoxBase. Oracle, and Paradox'). The prod:gious decrease in computing costs has also made compactness less of an issue, so that the storage of full original data in natural languag: form nowadays presents fewer technical difficulties, even though it inevitably leads to bigger files though it can still ciuse majo retrieval problems aliweusued, atmong others, by Rock and others. 1990). We therefore concentrate on the lollowing ways to decode ant retrieve from the [GBA s established format, by the use of today: software.
\end{abstract}

\section{Some options for implementing a data base}

One of the major aums of IGCP Project 23\%. in coordination witi the IUGS Subcommission on Data Bases for Petrology, has been t: develop ways of making the IGBA more accessible and user. friendly. so as to encouruge grcater fimiliarity with and use of the immense range of valuable information in the data base. from the

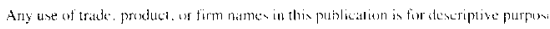

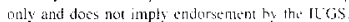

Table 1. - Comparison of four different approaches to implementing a dala base

\begin{tabular}{|c|}
\hline 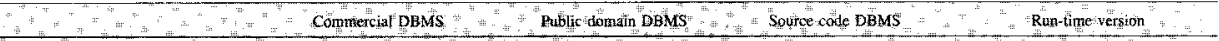 \\
\hline 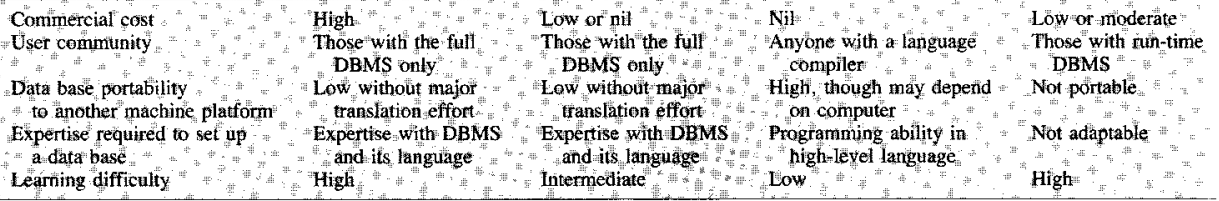 \\
\hline
\end{tabular}


programming point of view. there are several. often equally viable, ways of going about this. and it is appropriate to summarize their relative advantages and disadvantages (table $l$ and below), in order to establish why the particular course adopted here was followed. Alcernatives are heing actively investigated by other participants in the IGBA project, as also described briefly below:

1. Implement IGBA in a commercial DBMS. - A number of participants in 1GCP 239 have been developing working versions of the JGBA in dBase. probably the most widely used DBMS on IBM-PC and conpatible microcomputers. A major advantage of this approtch is that users experienced with dBase can make immediate use of a full working version of the IGBA. The corollary of course is that those without access to dBase or who are unable to use the program efficiently are not so well served. Even the relatively modest cost of dBase might restrict its promulgation in many of the Eatem Bloc and Third World countries who participated in IGCP 239. Even dBase devotees will also probably atmit that this particular DBMS has a steep learning curve, requiring an assistant' program for the inexperienced. Another disadvantage. not restricted to dBase, is that any commercial DBMS is itself changed outside the control of the user. reguiring the development, coordination, and distribution of comstant updates to maintain complete compatibility across users and to make une of significant new features. Furthermore, dBase is by no means the only major DBMS on the PC market; the equivalent project to IGBA in the sedimentary area (IGCP 296-SEDBA) has already decided to use a quite different DBMS, Paradox. Meanwhile, other major national and international geological data bases are being made available in different packages again, such as Oracle (for example, the Australian Burcau of Mineral Resources interlinked datal bases on igneous rock arialyses (PETCHEM), mineral deposits (NINDEP), and others). Although Oracle has the aldantages of being an international de facto DBMS standated, and protiding power support for distributed data hases, structured queries (via SQL), and so forth, it is even more complex and expencive than dBase. In short, the use of a fullfeatured commercial DBMS tends to restrict the applicability of any working data bise to those relatively few expers who have the particular soffuare, and it maty promote a proliferation of mutually incompatible and unintelligible versions of the same or of related data bases. Although. in theory, any data base can be translated between different DBMS via ASCII, this is still a complex alsk that requires the rebuiding of all the more sophisticated features of the data base other than the raw data themselver (including all imput-oucput procedures, preset queries, validation routines, and so forthi. The inevitable conclusion is that this approatch is limited in IGBA terms to platforms where a single DBMS hat not only achieved the status of a standard, hut is also widely avalabic at reasonable cost. These conditions are probably mei for $P C^{\prime}$-users, who have as a result achieved considerable success in implementing IGBA via JBase; for the reasons claborited below, we believe neither is mel with the Mucintush.

2. Use public domain DBMS or DBMS-like programs. - A number of such program are now available free, either with hardware or via nezworks and hulletin boards. One of the most exciting examples is Apple's Hyperard, an information managing program currently available free with Macintosh microcomputers. Hypercard allows the creation of "stacks" of interlinked "cards' (or screens of information, in an approach that mimics some features of a DBMS. It has its own full-teatured Pascal-like programming latlguage (Hypertalk), which can itself be compiled. There has heen quite an explosion in the development of geological "stackware" using Hypercard. which now extends to numerous stacks on paleontology, mincralogy, and petrology in particular (Rock, 1991). The advantages of this over approach (1) are twofold: such programs (notably Hypercard) tend to be far simpler and casier to use than a full-featured DBMS, and they are free. For example, Chayes (1991) has already described a simple Hypercard IGBA decoder. IgbaHyp, that takes the raw IGBA format of smal] subsets from the data base and writes them in a more intelligible labulated form: the reverse direction is also possible.

3. Develop DHMS source code. - Developing a new DBMS effectivcly from scratch was the only practicable approach with all the early petrological data hases (for example RKNFSYS from Chayes 1982; CIAIR, PETROS from Le Maitre. 1982; and with IGBA itself, until recently). The FORTRAN source code still made available with the IGBA base is atso free, and it can be implemented by anyone with at modicum of programming knowledge (and the relevant FORTRAN compiler) on any computer. It can also, of course, be adapted and recompiled to individual user's requirements. with commensurate forfeit of interchangeability. For the many geologists lacking programming expertise. compiled versions can easily be made available, in theory. for particular machines. The disadvantage of this approach is that the full sophistication of a commercial DBMS is simply not available without Herculean programming effor-and the experiences of geological organizations have been that such an effort is rasely, if ever, cost-effective when conmercial microcomputer DBMS are now available off-the-shelf for the cost equivalent of a few days" programming.

4. Run-time version. - An approach that to some extent combines some of the above is avalable with some fbut not all DBMS. in which a data base is made available in compiled cexecutable) form. With some commercial DBMS (for example, 4th Dimension for the Macintosh), the interested user is only required to possess a run-time version of the DBMS itself, which is far less expensive than the full version; with some others (for example. Clipper for PCs). even this is not required. For the run-time data base is a self-contained, compiled progran. The downside of this approach is that the run-time program cannot be adapted, modified, or improved in any way by its recipient.

\section{Towards a Macintosh version of the IGBA}

The Apple Macintoshe series of microcomputers has spread rapidly in the world of genscience - particularly in academia-primarily because of their exceptional ease of use. Matles have now reached the point where any self-respecting. internationaliy oriented product such as the IGBA needs to be available for the Macintosh. as a matter of course, as well as for PC and maitrame platforms. In working lowards such an implementation of the ICBA. all four ahove approaches were first considered in detail. On the hasis of substantial previnus experience in erecting other geological data bases via commercial Macintosh software (for example. Rock and others, 1990). it was decided that approaches (1) and (2) were not the best for a full retrieval program for the IGBA. on the following grounds.

- Among the various DBMS avalable for the Macintosh reviewed in depth by wheatley and Rock, 1989/, none has achieved the wide dissemination of dBase or even Oracle or other platforms: the choosing of one particular Macintosh DBMS would therefore inevitably testrict a Macintosh IGBA 10 an unacceptably small audience.

- These programs, though sophisticated and powerful, tend to be rather slow in operation and have a steep learning curve (at least in relation to other Macintosh software). 
- Completed self-contained run-time versions are not possible: a package must always be bought

As indicated above, approach (2) of the previous section has alteady been tested using Hypercart (Chayes, 1991), which bas proved to he a remarkably effective medium for a base-building (editing) program. However, we believe. along with Chayes himself, that it is likely to suffer from certain drawhactis if used for at base-exploiting (retricual) program. on the following grounds:

- The very substantial programming overheads associated with the user-friendly Hyperetrd interface mean that the program operates even more slowly than the Macintosh DBMS: in practice, Chayes (1991) estimates that it would require $7-8$ hours just to load the current about 15.000 samples (records, rocks) in the IGBA into IgbaHyp, and retrievals cannot be performed until this hats been done.

- The same overheads make the storage space of even relatively simple Hypercard stacks substantially (about 50 percent) larger than their precursor ASCII files. Although, as already indicated. slorage is not the problem it once was, it does mean that the size of at stack containing the full IGBA base would be over $8 \mathrm{Mb}$. whereas a specially written progran could work on the original ASCIl filcs $(5.5 \mathrm{Mh}$ )

- Hypercard"s programming language is not intrinsically designed to handle numerical querios of the type likely to be requircd routinely by IGBA users (for example. locate all analyses with $\mathrm{SiO}_{2}<50$ percent j. primarily because it handles numbers as character strings and not as real number or integers: although Chayes (1991) has found that retrievals afe still far more effective than might in principle be expected, there is still little doubt that Hypercard will be more cumbersome for nany types of retrievals than a program written in uny general purpose language.

Ior the above recisons, approaches (3) and (4) of the previous section have heen adopted. In fact, these two approaches merge here. because the Macintosh is such a spectal casc. Source code written for this machine is both extremely difficult to write (which reduces the number of experienced geologist practitioners to a very select fraternity!) and cannot he ported readily to other machines (or vice versa), becatse much of the code is taken up in implementing the many feitures of the WIMP (Windows, Icons, Menus. Pointers) interface.

\section{Introduction to the MacIGBA program}

The main aim of the present work has been to make available a user-friendly, stand-alone (run-time) program that decodes and interrogates the IGBA and that can be used almost immediately by anyone having a Macintosh. The source code was written in Think" Lightspecd Pascal version 2. We frealy admit that in providing a free Macintosh program we have nor overeome the problem of pronulgating the [GBA among those lacking the necessary Macintosh hardware. However, we believe this is a step in the right ditrection.

The MacIGBA is not a complete DBMS, becatse it deliberately Joes not dett with one of the most demanding parts of a dali-base job-the building, correcting, extending, and updating of the base itself. The reasons for this are discussed below. The MaciGBA is instead restricted to three important functions that allow anyone to use the base but not to change it: (1) to decode and display IGBA data in natural (genlogical) language: (2) to search for samples that match specified eriteria such as rock-lype, chemistry. mineralogy, and geographical or geopolitical location; (3) to extract (export) subsets of the base, ejther in the standard IGBA format or in a format more suited to processing in other Macintosh applications such at statistics or spreadsheet programs. The next section explains how to perform these three functions in turn. The Appendix performs the function of a reference manual, briefty explaining each of the menu: and menu items in the MacIGBA prograsn in sequence.

Four. and in some cases five, files are required for the MaciGBA to operate fitems (1) to (4) should be together in the sam. folder, whereas item (5) can be anywhere

1. The MacIGBA (the matin application

2. Refs.text a file containing bihliographic source malerial, which corresponds to file IGBAREF4 in the current tape vervion o: ICBA).

3. IGBA Codes fat folder containing six separate index files that an used to translate between IGBA codes and their decoded full-tex: equivalents). Programs have been written for building these inder files from simprle ASCII inņut tilcs.

4. An optional index file for the data-file being searched. This ha the syntax "filename index," and its use is explaincel below.

5. An ASCll cata-tile in IGBA format, which may be the complete base or a subset, as required. This must have only carriage-return: terminating lines, as is standard in the Macintosh world. and noi carriage-return/line-feed pairs, as is nombal in the $\mathrm{PC}$ world. iMany public dumain conversion progrtms are available 10 inter convert these alternative fonnats. such as File filter $\%$.

Although many operations in MitcIGBA work on a sequentialfile hasis. three specific operations require prior creation of the filename index file (4) above, namely; returning to the previou: record: going to a particular (numbered) record: and saving a file of trace element data in Macintosh format. This index is specific to eath IGBA file (complele base or extratt) but does not have to be created etich time a given IGBA filc in internogated. Once created. it cant the moved between machines in the nomal Macintosh way, provided it resides in the same folder as its parent file. If such a filc does not exist at the time a given dati-file is opened. MaciGBA will atsk (set fig. 4 whether it should be created straight away (indexing the complete IGBAI)AT4 I on a MacIIx lakes under 3 minutes, If one of the three specific operations is requested, when an index file has still not been created (or cannot be found in the cortect folder), the same dialog box will appear. If "cancel" is selected, the specific operation: will be aborted.

The reason MacIGBA does not include a data-base building or editing facility is that the JGBA was designed to be centrally handlec via the IGBA office and distributed via World Data Center-A: it is therefore essential to retain only one "cican" master copy, at all times, that incorporates all corrections and additions to the date of general tssue. To huild an editing facility in MaciGBA would temp! users into creating innumerable variants of this master copy. which would then be impossible to coordinate.

Throughout the remainder of this text, menus within MaclGBA are identified by angle brackets >, individual menu items by fourl: brackets\}, butonts and teuns by [square bracketsi. and keyhoard key by |vertical bracketsi.

\section{Browsing through decoded IGBA data}

Launching MacigBA results in the presentation first of a startur screen (fig. 1) and then of a standard Micintosh dialog box requesting the user to choose the inpus 1GBA-format data-file, which may be a subset or the complete base (fig. 2). This dialog can be returned to at any tine to choose a new IGBA data-file. If the data-file is not in the correct IGBA format. a warning message is presented (fig. 3) and the process aborts. The user is also asked whether an index should be created at this slage, if one does not already exist (fig. 4). After this. the first record in the chosen data-file is decoded and the data for that sample displayed (fig. 5 r. 


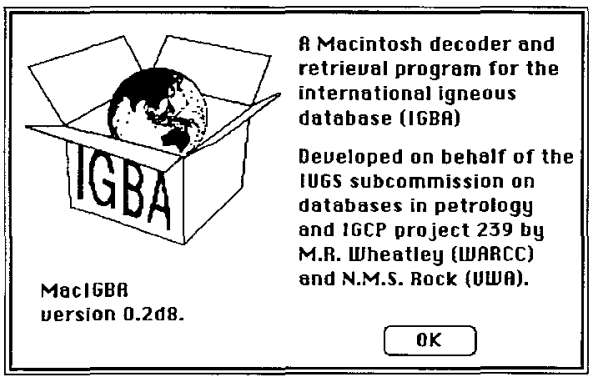

Figure 1.-Start-up screen for MacIGBA.

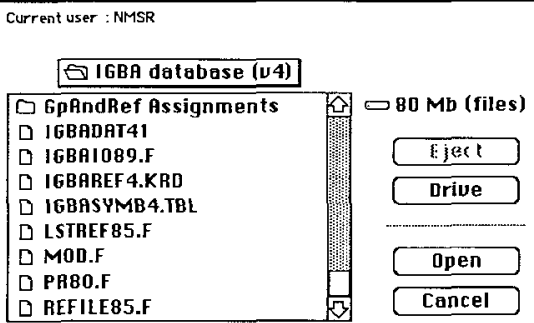

Please choose your IGBA dota file:

Figure 2.-Standard Macintosh dialog initiated on startup, for choosing the name of the input JGBA-format ASCI file.

The top of figure 5 displays general information. If an index file already exists, the sequential number of the sample in the data-file will be displayed at the top-center (as in fig. 5). Other information includes both the rock-type as specified in the original reference, and the IGBA number and corresponding rock-name. Remaining information is displayed in lists. most of which are scrollable. The left-hand list contains the major oxide analyses, the author's total, and a calculated total as a check (the sum of the major oxides-note that discrepancies as in figure 5 are horrendously common?). The upper central list contains any decoded trace element data. Analyses shown as "element ?" signify that only a trace of the element was detected. A figure in brackets to the right of an analysis identifies the bibliographic reference from which the analysis is derived. The same convention is used in other lists. The right-hand list decodes the mincrals identified it the specimen. Any mineral information flags are expanded into descriptions appended to the mineral name. All remaining information is displayed in the botton-right list. This includes status. age, petrographic descriptors. and additional information. Wherever possible. codes used in the IGBA are expanded into normal genlogical English. However. text in any of the lists may be truncaled if there is insufficient space for it 10 be displayed;

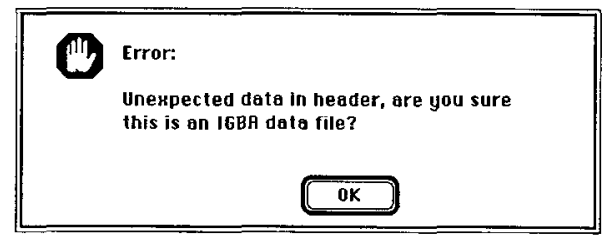

Figure 3. - Warning message indicating that the chosen data-file is not in the appropriate IGBA format.

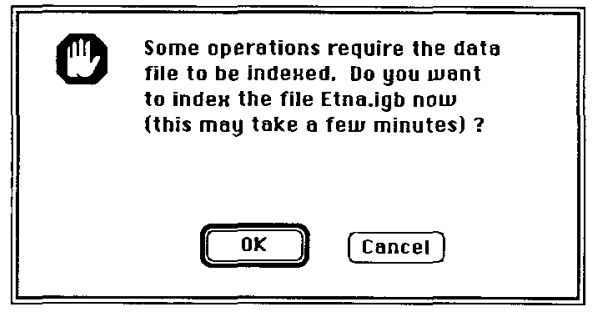

Figure 4.-Dialog box asking whether to generate an index file.

clicking on any lite of information in a list will then display the unabbreviated text at the bottom of the window.

Three icons are displayed on the right of figure 5 . The [bookicon| accesses source reference data (fig.6). Which are presented in the IGBA as two record preface cards preceding each block from the same source reference( $s)$. Each reference is numbercd and provides a cross-reference to the displays in figure 5 . The [next recordl icon (arrow) displays the next record in the active data-file that matchics any search criteria that have already been set (see next section), or the next sample sequentially if none have been set. The lglobel icon displays a small world map with crosshatirs revealing the sample location (fig. 7). The original IGBA ASCII format from which figure 5 is decoded can also be vicwed (fig. 8). This can be useful to check whether a possible error in interpretation is in fact an error in the IGBA data-file.

\section{Searching the IGBA}

Eight retrieval mechanisms are provided in MacIGBA, described below. Any number of these can be active at once, in which case they are chained that is, separate criteria are Bonlean ANDed together). The one conceivable type of IGBA searching currently awaiting implementation is searching based on sample age; this reflects the complexity of the required parsing in IGBA and the need to devise an "intelligent" module to handle it. We hope to implement age searching in later versions.

- Searching by rock-type (fig. 9),... The window displays two scrolling lists of names. The left-hand alphabetical scrolling list contains all the names used in IGBA, while the right-hand is initially empty. Copying onte or more of these names into the right-hand list specifies the rock-type(s) to be located. Clicking on 


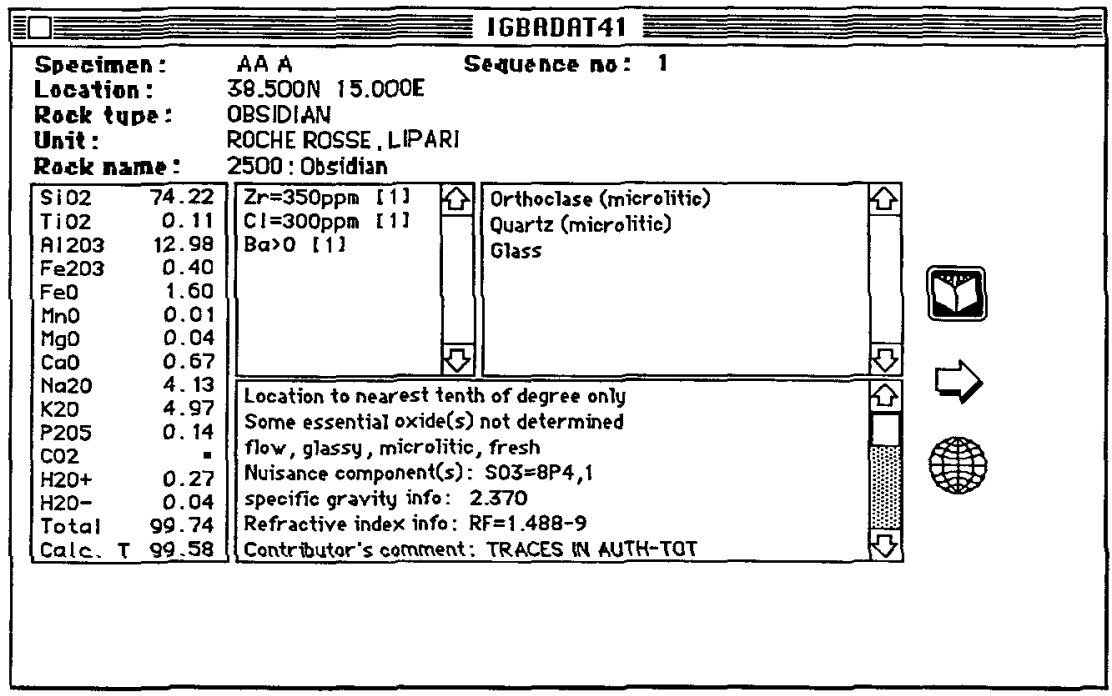

Figure 5. - The main display window for the first sample (record, rock) in the complete IGBA base (file IGBADAT4I). See text for explanation of lists and icons on right. Note that missing data (in this case for $\mathrm{CO}_{2}$ ) are automatically decoded to the standard Macintosh "bullet" character (ASCIl code 165, keyboard option-8), so that MacIGBA preserves the distinction between "not analyzed" (missing data) and "not detected" (analyzed but below detection limit).

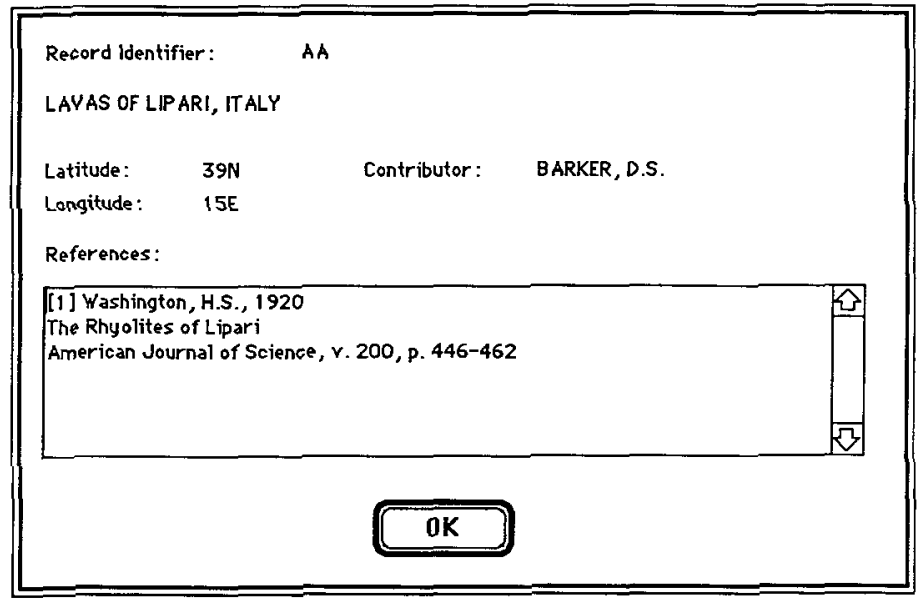

Figure 6. - Window displaying bibliographic data for the sample displayed in figure 5. 
$[O K]$, followed by the [nest sample right arrow icon in figure 5 . which therl reappears. will then begin the search for the next record that actualy matches thesc rock-typersi. Note that the active file is searched sequentially from the current position; an option is included we return to the top of the file as required. If several rock-types are chosen, as in figure 9, the search is a Boclean. OR. that is, sarmples matching any of the chosen rocktypes are selectedy. becatuse of course a given sample cannot correspond to more that one rock-type.

- Searching by location (fig. 10). - The window displays the same map as in figure 7 . but rectangle(s) can here be drawn to select exarch regrion(s). This method works well for continents and large or isolated countries ffor example. Antarctica. Australia. New Zealand. North America), and for some oceanic islands, but it is nor really effective for small, densely packed, or irregularly spaced countries (for example, Belgium. Liechtenstein), which are hetter located using the place-name method described bolow and in tigure 13.

- Searching by major elenent composition (fig. 11).-Minimum and maximum values can here be entered for one or nore oxides (fig. 11). Only samples whose chemistries lie within the specifie-

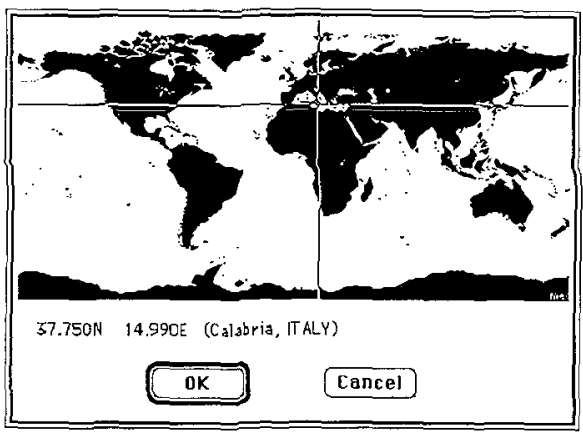

Figure 7.- Window showing the location of the sample displayed in figure 5 . drange(s) will then be located. When more than one oxide has been specitied, the search is a Boolean . A.ND. - that is, all of the cxides must be in the specified renge. A Boolean. OR. that is, at least one of the oxides in the range) is easily done via separate searches, one oxide at a lime. Combinations of .AND, and .OR. have not been implemented in this or other MaclGBA search mechanisms, becanse of ambiguities that would unavoidably arise in any menu selection format.

- Searching by mineral assemblage (fig.12). - Selecting by mineral is slightly more complicated than selecting by rock-type. because of the fact that the IGBA codes minerals hicfarchically (for example, $\mathrm{N}=$ feldspar, $\mathrm{NF}=$ mictodine). The windows in figure 12 display three lists: one each for mineral groups (top left) and species (bottom left, and one for items selected (right). Initially, only mineral groups will appear in the top-left list, with the other two lists empty. If any mineral group (one-letter code) is then selected in the top-left list, its constituent mineral species (two-letcer codes) will appear in the bottorn-lett list (fig. 12A). Names can then be copied across from the left to the right lists in a similar manner to the rock search procedures, described above. If mineral group codes are copied across, records with either the mineral groups or any of their constituent mijeral species will be retrieved; if mineral species codes are copied across. only records with those species will be retrieved (as in fig. $12 \mathrm{~A}$ ). A pair of radio buttons (bottom of fig. 12) allows specification of whether the located rocks should contain all of the nominated mineral groups/species (.AND.), or at least one of them (.OR.). Finally, [Lookup! enables direct searching of the IGBA mineral code index itself (fig. 12B).

- Searching by place name (fig. 13).--Searching by place name is similar to selecting by mineral assemblage. Most of the records in the IGBA data base have their location coded using another hierarchical schene called FIPS (NBS, 1990). which encodes all the world's genpolitical regions and subregions (countries, states. island groups. and so forth) by the use of four letters (the first wo for majot regions like countrics (tor example. LS for USA), the other two for subdivisions like states (tor example. CSO6 is Cali[ormal. The window (figure 13 initially displays two-letter codes and country names in the top-left list, selecting on any of which will bring up that country's consituent states. provinces, and so forth. in the bottom-leit list, as in fig. $13 \mathrm{~A}$. As with mineral searches, |Lookupl enables direct interrogation of the complete FIPS code index (fig. 13B). Unlike mineral searches, however.

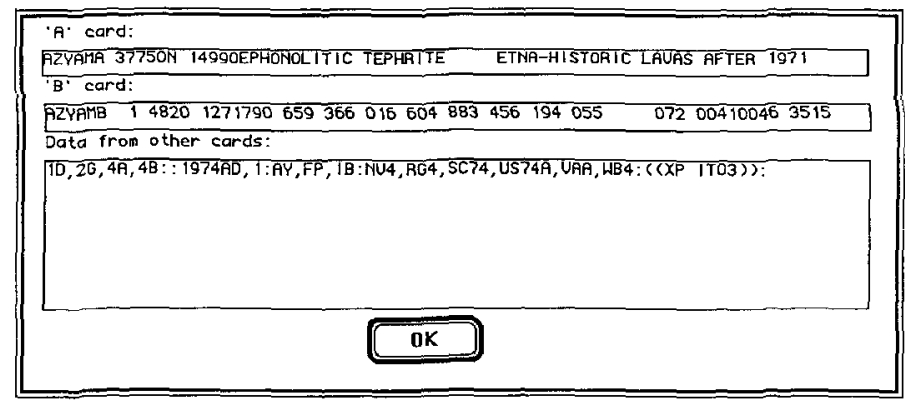

Figure 8. - Window showing the original IGBA-format ASCII record for the sample displayed in figurie 5 . 


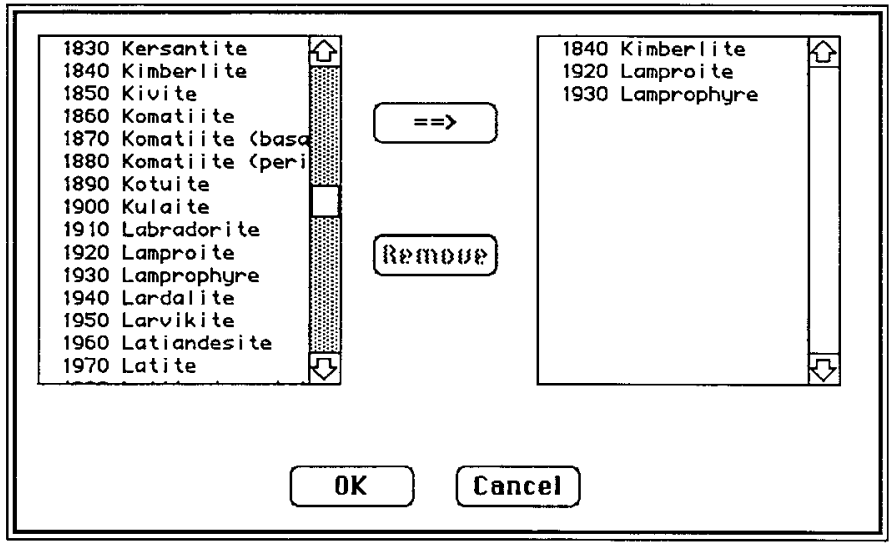

Figure 9. - Window for defining target rock-types. Three alternative rock-types have been selected here (Kimberlite or Lamproite or Lamprophyre). Rock-types are selected from the left-hand scrolling list by clicking on the name, by using the $\uparrow$ or $\downarrow$ keys on the keyboard, or by typing the first few characters of the rock-type on the keyboard. The name is then copied across by clicking the $I==-1$ button or by hitting return. Rock-types can be removed from the right-hand list by selecting them, then clicking in the [Remove] button. When the appropriate rocks have been selected, clicking the lOKJ button (or |enter key) will confirm the selection and return to the main sample window (fig. 5). Hitting the Enter key is equivalent to clicking $[O K J$.

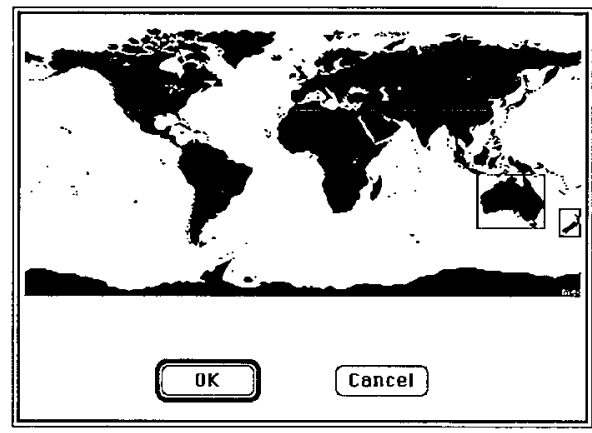

Figure 10. - Window for defining target areas. Two alternative areas have been defined here: Australia or New Zealand. One rectangle is drawn by clicking and dragging with the Macintosh mouse in the usual way. The shift key is held down to drag out more than one rectangle, as here.

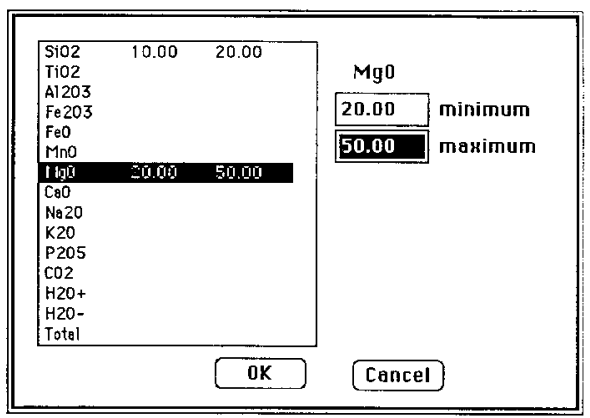

Figure 11.-Window for defining target major oxide chemistry. This example locates rocks with both $\mathrm{SiO}_{2}$, in the range 10-20 percent, and $\mathrm{MgO}$, in the range 20-50 percent. The i or $\downarrow$ keys can be used to move up and down the list of oxides, and the |return or $\mid$ tab keys $\mid$ to move between the minimum and maximum values. Hitting Enter is equivalent to clicking $/ O \mathrm{~K}]$. 
n : FELLISFFF

$0:$ FELDSPATHOID

$P$ : PHYLLOSILICATE

Q : AMPHIBOLE/AMPH IBOLOID

R : PYROXENE/PYROXENOIDS

S : OLIUINE

$T$ : OTHER SILICATE

$\mathrm{U}: \mathrm{OXIDE}$

N1: Albite

N9: Other Feldspar

NR: No mineral info.

NB: Feldspar

NC: Alkali feldspar

ND: Anor thoclase

NE: K-Feldspar

NF: Mizrouel iniz

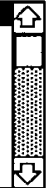

$==$

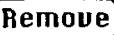

$==>$

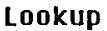

ND: fnor thoclase

$\mathrm{NF}$ : Microcl ine$$
\text { . }
$$

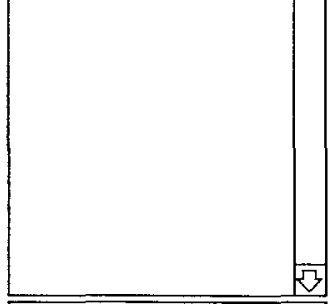

1

\section{Find rocks containing all of the selected minerals}

Find rocks containing at least one of the selected minerals

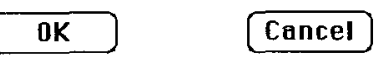

N:FELDSPAR
D : FELDSPATHOID
P : PHYLLOS IL I CATE
$\mathrm{Q}:$ RMPHIBOLE/AMPHIBOLOID
$\mathrm{R}:$ PYROXENE /PYROXENOIDS
$\mathrm{S}:$ OLIUINE
$\mathrm{T}:$ OTHER SIL ICATE
$\mathrm{U}:$ OXIDE

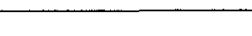

.

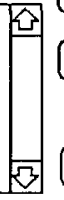

N :FELDSPAR

NB :Feldspar

O :FELDSPRTHOID

DA :Feldspathoid

$==$

Remoue

$==>$

Lookup Feld

Find rocks containing all of the selected minerals

O Find rocks containing at least one of the selected minerals

OK

Cancel

B

Figure 12,- Window for defining target mineralogy. A, Use of the hierarchical IGBA codes to specify rock containing either anorthoclase or microcline. B, Ese of the [Lookup] button to locate all minerals in the IGBA system with the four-letter character siring "Feld." Clicking on any mineral group in the top-left list will reveal corresponding mineral species in the bottom-left list. Similarly, clicking on any entry in the right-hand list will generate corresponding entries in the other two lists. Items can be added to the right-hand list by selecting in the left-hand lists and clicking the upper or lower [-->], and removed by selecting in the right-hand list and clicking /Removel; standard shift-click Macintosh operations will select a range of items. Typing Return is equivalent to clicking on [Lookup] and typing |Enter| to clicking on $[0 K]$. 


\begin{tabular}{|c|c|}
\hline $\begin{array}{l}\mathrm{AL} \\
\mathrm{AN} \\
\mathrm{AO} \\
\mathrm{AQ} \\
\mathrm{AR}\end{array}$ & $\begin{array}{l}: \text { ALBANIA } \\
: \text { ANDORRA } \\
: \text { ANGOLA } \\
: \text { AMERICAN SAMOA } \\
\text { : ARGENTINA }\end{array}$ \\
\hline $\mathrm{HE}$ & : FIIETFHLIA \\
\hline $\begin{array}{l}\text { AT } \\
\text { AU }\end{array}$ & $\begin{array}{l}\text { : ASHMORE AND CARTIER IS. } \\
\text { AUSTRIA }\end{array}$ \\
\hline
\end{tabular}

ASO 1: Australian Capital Terr. ASO2: New South Wales ASO3: Northern Territory ASO 4: Queensland AS05: South Australia

AS06: Tasmania AS07: Ujctoria AS08: Western Austral ia

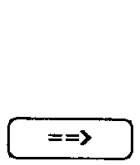

Remove

$==>$

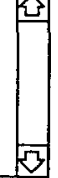

Lookup

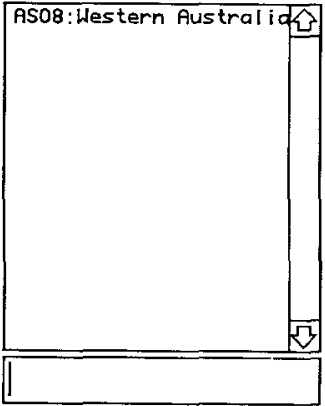

\section{Cancel}

$=\Rightarrow$ CJO8: Western

El 29: Westmeath FJ05: Western GR05: Western, Gambia GHO9: Western IN28: West Bengal JM16: Wes tmore land KE09: Western NZB3: Wes t l and PPOS:

Lookup Lilest

Figure 13. - Windows for locating target source localities from the FIPS code. A, This example will locate rocks from Western Australia. A ustralia has been chosen in the top-left window, which automatically brings up all constituent States and Territories of Australia in the bottom-left window for selecting into the right-hand window. B, Here, [Lookup] has been initiated for the word "West," which has located all FIPS items with this character string. 


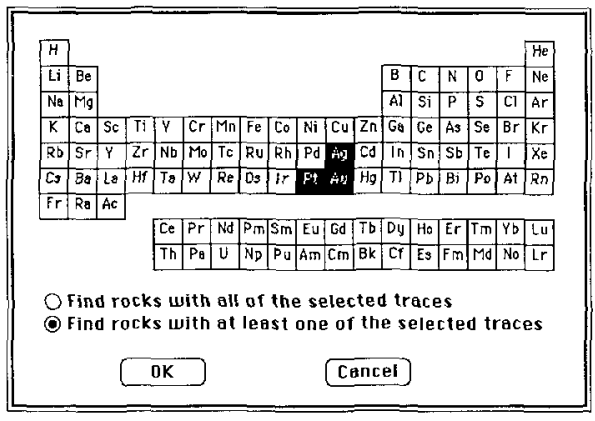

Figure 14.-Window for defining target trace element data. This example locates rocks with data for Au or Ag or Pt.

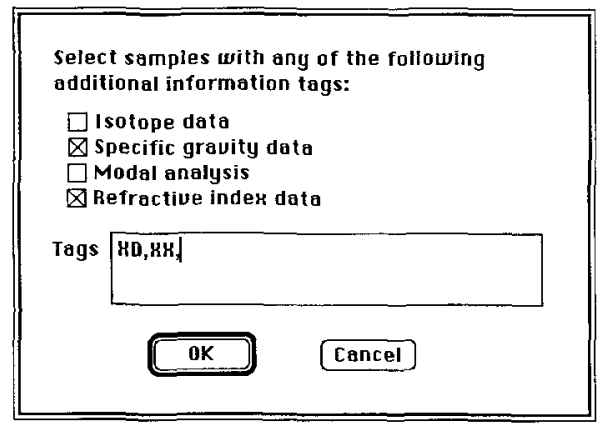

Figure 16.-Window for targeting additional information tags. This example selects rocks with either specific gravity or refractive index information. The corresponding ags $X D, X X$ have been inserted automatically by MacIGRA.
Figure 15. - Window for targeting specific IGBA siatus codes. As in previous windows of this type (figs. 9, 12, and 13), selecting an item in the left-hand scrolling list and clicking [Remove] will move it to the right-hand hist. Clicking [OKJ (or typing Enter|, will then confirm the selection and return to the main window (fig. 5 ).

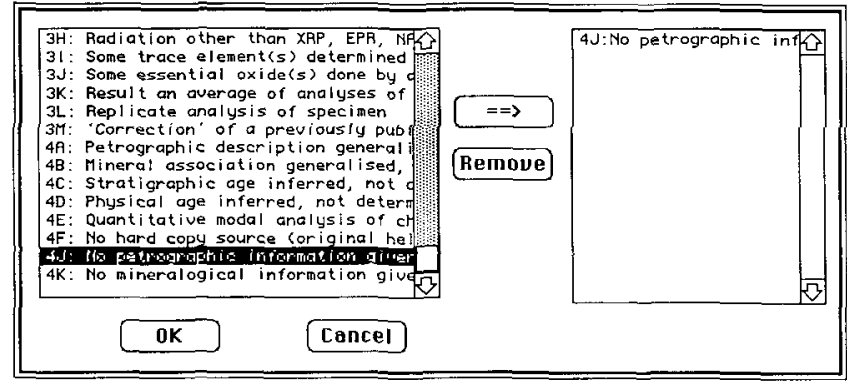

copying several entities to the right-hand list will always result in a Boolean. OR, search, with rocks from any one of the nominated regions/subregions being selected; an . AND. search is clearly abutd here. as a sample cannot be fron severnl places at once.

- Searching by trace element analyses (fing. 14).-This option displays a periodic table, from which any element(s) can be selected. Rocks that include analyses of the relected trace elements will then be located. As with searches by oxide and mineral assemblage. retricveli can be on all of the selected trace elements (Boolean AND.1, or on at least one of them t.OR.). Note, however. that this search method simply decrmines the existence of data for a particular trace element(s); it does not allow searching by range of value (see lig. 11).

- Searching by status codes (fig. 15).-The IGBA specifically Tags cortain types of information (or. more commonly, missing information about a sample record using a two-character status code: for cxample. imprecise locations (1A. IB. IC), major element data normalized to $] 00$ percent $(2 \mathrm{~B}) . \mathrm{H}_{2} \mathrm{O}^{\mathrm{i}}=$ loss on ignition 12G). or as in figure 15 , rocks with no petrographic information given (4J). This option allows all records with a particular status code to be located.
- Searching by additional information tfig. 16).-The tinal section of an IGBA data record contains ar additional information list. Each item is categoriced by a two-chatacter tag (for example. $X \mathrm{X}-$ specitic gravity data or $\mathrm{XI}=$ isotope data), and Macl(sBA can locate records with any specified tag. The tatg for four common items in the additional information list can be selected easily by cicking in the four theck boxes labeled isotope. specific gravity, modal analysis. and refractive index (fig. 16). This will then atutomatically insert the appropriate tag codes into the edit box. Other codes an be typed itr. as required, by reference to the full code list enumerated in JGBA Circulars. Each tag should be separated with a conma. For cxample. Deep Sea Drilling Projectsamples can be located by searching for additionul information tags "XS" and " $\mathrm{S}$ ". The search here is Boolean .OR. - at least one of the specified types of information must he present.

\section{$\overrightarrow{E x t r a c t i n g ~ a n ~ I G B A}$ subset}

The third of the MaclGBA functions, saving a subset of IGBA. will write data for all samples from the current file that match the cument 


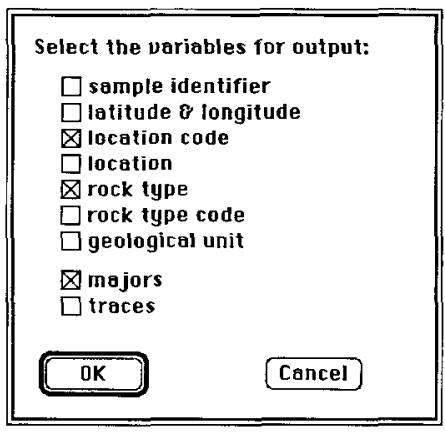

Figure 17.-Dialog box for exporting a subset of the active data to a new output file. The outpat file format is here set to IGBA, to create an IGBAformat ASCII data-file.

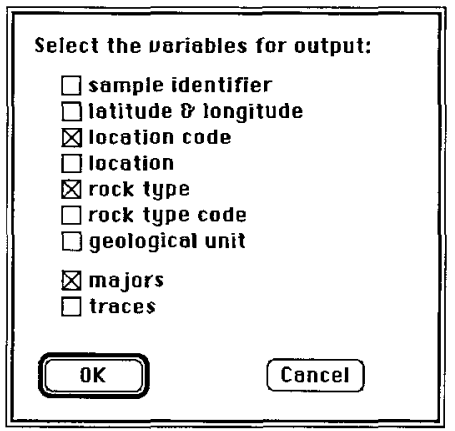

Figure 18.-Dialog box for selecting what information is output to a new Macintosh-format export file.

search criteria (preset via figs. 9-15) to a new file. A standari Macintosh file selection dialog box is first displayed to set the name of the export file (fig. 17). The new file format can also be specified here. Two formats are provided:

- IGBA format - An ASCI file in the stindard IGBA coded format (sec fig. 8). This is the only file format that can be read back into MaciGBA for subsequent processing.

- Macintosh format - A tab-delimited Macintosh file containing names of the variables $\left(\mathrm{SiO}_{2}, \mathrm{Ba}\right.$, and so forth) in a first label line. followed by data in subsequent lines, one line per sample. This same format is also used by most recent Macintosh software. geological or otherwise. including that developed by the present authors (for example, Wheatley and Rock, 1988). Major clements are listed first, then trace elements (ii selected) are listed alphabet-

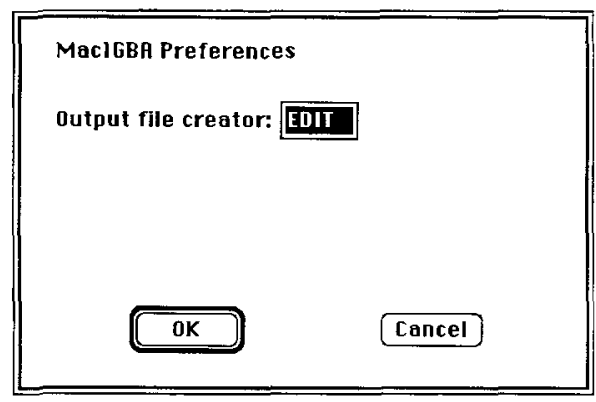

Figure 19. - Dialog box for setting creator signature for Macintosh output files; defaull (shown) is EDIT (that is, ASCII "TEXT" file). Other useful types are STAT (Statview), CRGF (Cricket Graph), XCEL (Excel), and MSWI (Microsoft Word).

ically. Samples with no data are omitted. Values of " $<\mathrm{X}$ " are coded as 0 ppm. Missing data for a particular element are coded as

" " [ASCII 165, the standard Macintosh code for missing datal.

If Macintosh fornat is selected, a further dialog box (fig. 18) allows the user to detemine which of the many IGBA information fields is exported. The creation of a new file containing trace clement data is a two-pass process through the data file: on the first pass. the number of different trace clements analyzed in the matching samples is determined; and on the second pass, the data ate actually written to the export file. The export can be intermpted at any time by use of the standard Macintosh /control-full stop/ sequence. Whether an export is allowed to proced to completion or not, the user is automatically informed how many records have been written to the new file.

Exported Macintosh files are written by default with creator signature "EDIT" (that is, Macintosh ASCII "TEXT" format) and can be opened directly and used immediately by Edit, itself. by any text-cditor like QUED/M, or they can be imported into any Macintosh data-processing application with a reasonably intelligent textfile import procedure (for example, Data Desk, Excel, or Statview II). In the latter case, the file must be opened from within the application rather than by double-clicking on the file itself. Other creator signatures can be selected using a \{Prelerences\} option (fig. 19). provided the user knows the defined Macintosin code for that particular program. For example, typing STAT in the box on figure 19 will create an output file that Statview will recognize and be able to open directiy upon double-clicking the lite itself rather than having to import the file from within Statview. Figure 20 shows a file resulting from the dialogs in figures 16 and 17 , after importation into Statview via either method.

Exactly what will result from double-clicking directly or inporting indirectly does depend to some extent on the application being used. For example. Statview is sophisticated enough to recognize the initial label line in the MacIGBA export file as containing the names of the variables (columns) that will then become headers to the file (fig. 20), whereas Cricket Graph and Excel cannot distinguish labels from data and will place the labels as data in row 1 of their spreadsheets. Some other applications cannot deal with initial label lines al all and throw up errors on import: in such cases, creator signature "EDIT" should be used and the initial label line edited out first (for exanple, in Edit). 


\begin{tabular}{|c|c|c|c|c|c|c|c|c|c|c|c|c|c|c|c|c|c|c|c|}
\hline 国 & & & & & & & $=$ & BA & ustr & alia & & & & & & & & E & \\
\hline & Seque... & Loestion & Poek Type & $\mathrm{SiO} 2$ & TiO2 & $\mathrm{Al203}$ & Y.203 & 7.0 & MoD & $\mathrm{MgO}^{\circ}$ & $C_{2} O$ & $\mathrm{H}_{2} 2 \mathrm{O}$ & $\mathbf{K} \mathbf{O}$ & 1205 & $\mathrm{CO2}$ & $1120+$ & Hois- & Totul & \\
\hline 1 & 301 & NSW & Tesedenite & 44.78 & 2.49 & 14.03 & 4.15 & 9.15 & .14 & 9.57 & 8.12 & 3.30 & 1.77 & .62 & - & 2.05 & .19 & 100.31 & \\
\hline 2 & 302 & RSW & Feschesine & 44.73 & 2.56 & 14.42 & 2.93 & 9.51 & .15 & 8.08 & 8.31 & 3.60 & 1.96 & .64 & - & 2.89 & 89 & 100.03 & \\
\hline 3 & 320 & KST & Dasalt & 45.63 & 2.04 & 14.54 & 1.98 & 10.21 & .19 & 9.18 & 9.83 & 3.46 & 1.04 & .50 & $\cdot$ & 1.09 & 50 & 10025 & \\
\hline 4 & 321 & NSW & Busale & 42.07 & 2.57 & 11.24 & 5.08 & 7.92 & .18 & 8.81 & 8.53 & 3.65 & .32 & .57 & .21 & 5.12 & 8.57 & 100.05 & \\
\hline 5 & 322 & NSW & Bassur & 46.80 & 2.61 & 16.93 & 1.76 & 7.99 & .12 & 5.32 & 10.48 & 3.95 & 1.00 & .54 & .07 & 1.40 & . $5 \hat{0}$ & 100.07 & \\
\hline 6 & 323 & NSW & Dolerite & 46.97 & 3.49 & 15.04 & 2.59 & 9.12 & .16 & 2.56 & 6.82 & 6.54 & 2.12 & 1.26 & .10 & 2.86 & S4 & 100.17 & \\
\hline 7 & 324 & NST & Dolerite & 48.50 & 3.04 & 15.53 & 2.90 & 8.28 & .15 & 4.45 & 10.14 & 3.90 & 1.05 & .66 & - & .95 & .48 & 100.03 & \\
\hline 8 & 841 & Nomis & Gnsophyre & 57.70 & 1.43 & 15.16 & 3.76 & 7.54 & .20 & 1.20 & 6.56 & 2.65 & 1.82 & .21 & - & 1.87 & 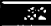 & 100.42 & 3 \\
\hline
\end{tabular}

Figure 20.-Extract of a Macintosh file exported from MacIGBA using the dialog in figure 18 and then imported into Statview $I$. Samples are those from Australia. Each column (field, variable) is separated by a tab character (ASCII 13), each sample (row, record, rock) by a carriage-return (ASCII 9). The initial label line in the MacIGBA export file is automatically recognized by Statview

\section{Speed and storage requirements}

In order to estimate its general usefulness to the global community. VaclGBA has been brictly tested for speed. To optimice speed, two versions have been writlen for Macintoshes with and without coprocussors. To warch through the entire current data base (IGBADAT41) if 14,722 records currently takes a little under 3 minutes on an $8 \mathrm{Mb}$ Macintosh IIx (using 881 version of MaclGBA), running the base rom an external hard disk, and just over 7 minutes on a standard 1 Wh Macintosh SE rusing normal version), running the base from a PL/ removable hard disk. Searching for a place name simnilarly takes about 6 minutes on the IIx and 26 minutes on the SE. These times are considered acceptable for metningful interaction and extraction from IGBA and will of course be substantially shortened on faster machines or on subsets of the base. Because the files have to be vearched sequentially, matters are obviously speeded up if the samHes required happen to be nearer the top of the active data-file.

As the complete IGBADAT4 I ASCII bate itself occupies about $5.5 \mathrm{Mb}$ of dish space. MaciGBA can clearly only interrogate it on a Macintosh equipped with a hatd disk, although subsets of $1.4 \mathrm{Mb}$ or ess $(800 \mathrm{~h}$ or less for older machines) will of course be usable from loppy disks. The MaciGBA software itself only requires $68 \mathrm{k}$ of disk pace and a recommended $500 \mathrm{k}$ of RAM. but the Codes folder and Rets, list files require an addition $324 \mathrm{k}$, so ruming on a standard dual-floppy $1 \mathrm{Mb}$ Macintosh is clearly asking a good deal of the machine!

\section{Availability}

Dikk copies of a B-releane of execurable MacIGBA. sample IGBA lata files, and this paper are available free of charge to any interested tser. on receipt by the authors of at least one Macincosh 3.5-in. diskelte plus an addressed envelope, and US\$10 (10 cover costs of reproduction and postage onlyy in an international postal coupon or nominal funds in exchangeable currency (for example. CS\$10 note. io personal checks please). Users in the USA can obtain copies, under the same preconditions, from Professor F. Chayes (Chairman. HGGS Subcommission on Data Bases for Petrology. Smithsonian mstitution, Dept. Mineral Scicnces MS119, Washington, D.C. as containing the names of the variables and is therefore read as column headings rather than as part of the data. Double-clicking on the exported file is sufficient for Statview to recognize and launch it. Note that missing $\mathrm{CO}_{2}$ data are distinguished by bullets, as in figure 5.

20560, USA, e-mail: chayes (a simsc. bitnet) or Dr. J. Frizado (Chairman IGBA project, Dept. Geology. Bowling Green Unjersity. Ohio 43403. USA; e-mail: frizado(a andy bgsu.cdu). When the program has been adequately $B$-tested, it is hoped that MacIGBA will be distributed along with the IGBA itself, which is already avajable from World Data Center-A. NOAA/NGDC, Building E/GC3, 325 Broadway, Boulder, Colorado 80303-3328, USA. Macintoshreadable copies of the complete IGBA base are unfortunately too large to be sent even on 1.4 Mb diskettes (even in compressed format), but they can easily be extracted from the magnetic tape available from World Data Center-A. The possibility of eventual distribution on CD-ROM is being looked into.

\section{Explanation of individual menus and menu items in MacIGBA (in order of appearance)}

The complete menus and their contents are displayed in figure 21 . Sone items are permanently disabled (greyed out). such as all exccpt \{Copy\} in the <Edit> menu, but depending on the precise situation. others may be enabled (black) or disabled (grey), is explained bclow.

\section{$<$ File $>$ menu}

\{Open data file\} --Displays at standard Macintosh file selection dialog box for selecting an input file (fig. 2). The file must be an IGBA-format ASCII file with carriage-returns only at the end of eich line; if this is not the case, a warning message is presented (fig. 3). This item will be disabled (greyed out) as in fïgure 21 . once a file has been successfully opened. At present, only one IGBA ASCIl-format data-file can be opened at once, so this menu will be dimmed. once such a tile bas been opened.

Close data file\}-Closes the active IGBA file the one whose window is frontmost. The standard Macintosh close box in the topleft of the active file's window will perform the same function.

\{Index data file\} - If an index file already exists for the active datatile. this menu item will be disabled, as in figure 21 . If not, this item initiates a dialog (fig. 4) to generate such an index, as is required by some of the retrieval operations (previous sample, go to sample, and saving trace clement datia in Macintosh format). 


\section{File Edit Find Display}

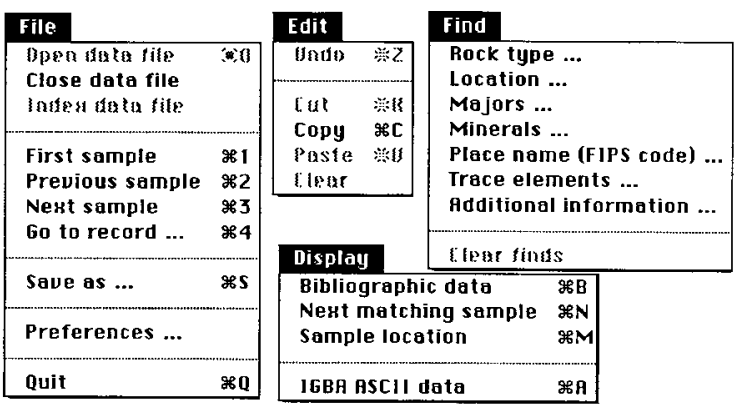

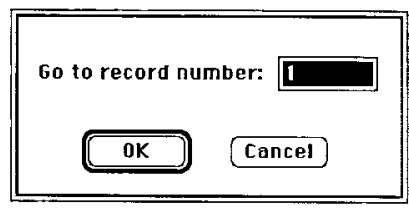

Figure 22,-Dialog box for going to a particular indexed sample number.

Figure 2I. - The main menu bar and contents of the four Mac/GBA menus.

The same dialog will aiso be automatically initiated the first time one of these operations is selected and an index file for the selected data-file (filename. index) cannot be found.

\{First sample\}, \{previous sample\}. \{next sample\}-These perform exactly the same functions as the equivalent menu items in Hypercard: namely fijst sample\} reads the very first (top) sample (record) in the active file. \{next sample\} reads the next sample record sequentially, and so forth. Note the difference from the [Next sample' here, which goes to the next sample irrespective of any selection criteria, and the [next sample] right-arrow icon in figure 5 or its equivalent \{next matching sample\} item in the $\measuredangle$ Display $>$ menu (fig. 21). which select only the next sample that fulfills the current selection criteria, skipping those that do not. The \{next sample\} and \{next matching sample\} items are equivalent only if no search criteria have been specified. \{First sample $\}$ can be used to return to the top of the active data-file when making a new search, or when completing a search that began in the middle of the active data-file. \{Go to sample\} will achieve the same result (see next entry). There is currently no direct option for selecting "last sample," as in Hypercard, since this would not seem to be a particularly useful operation in MacIGBA. However. it can be sinulated by selecting $\{G o$ to sample\} (next entry) and choosing a large number (that is, larger than the number of indexed samples in the rile).

\{Go to sample. . . Initiates the dialog in figure 22, allowing direct access to a particular sample in the file. This can also be used to locate the last sample or the totai number of indexed samples in the fite. simply by responding with a large number.

[Save as. . - Initiates the dialog in figure 17. for saving samples from the active IGBA file as a separate file, in IGBA or Macintosh (tab-delimited) format (use the pop-up menu at bottom of figure 17 to determine format $\mathrm{i}$. If no selection criteria have been specified. the entire active file will be saved. If selection criteria have been specified, the menu item changes 10

\{Save matching samples as\}, and only samples matching the uriteria will be saved. If Macintush format is chosen. the dialog in figure 18 will also then appear, to determine what extract of information will be exported to the new file (see lext for further details).

\{Preferences. . . Initiales the dialog in figure 19 for choosing the filetype for a Macintosh output data-file. The default (as in fig. 19) is EDIT, a simple ASCII "TEXT" file, readable by Edil and many other Macintosth programs, but any other delined Macintosh fourletter signature can be inserted here for example, XCEL for Excel. STAT for Statiew, CRGF for Cricket Graph, MSWD for Microsoft Word. whereupon any output files will be readable by the chosen program. The set preferences are not saved when the user quits the program.

\{Quit\}-Quits to the Macinonsh Finder in the usual way.

\section{$<$ Edit $>$ menu}

Only the \{Copy\} menu is enabled. This will copy any selectable highlighted item to the clipboard in the usual Macintosh way. For example, in figure $13 \mathrm{~A}$, selecting this jtem would copy AS: AUSTRALIA to the clipboard.

\section{$<$ Find $>$ menu}

Items actively selected from this menu will have a next to them. \{Rock type $\}$-Initiates the dialog in figure 9 , for selecting specified rock-types from the active IGBA file.

\{Location\}--Displays the world map in figure 10, for selecting samples from specified regions from the active IGBA file. Cis: the Macintosh mouse iclick-and-drag/ to specily rectangtalar areas,

\{Majors\}-Initiates the dialog in figure 11 . for selecting samples with a specificd range of chemistry from the active IGBA file.

\{Minerals\}-Initiates the dialog in figure 12 . for selecting samples containing a specified mineral or suite ol mincrats from the active IGBA tile.

\{Place name (FIPS code)\}-Initiates the dialog in tigure 13, for selecting samples from specified geographic regions or subregions from the active JGBA file (based on their herarchical FIPS indes as described in the text).

\{1race elements - Initiates the dialog in figure 14. for selceting samples containing data for specificd trace clementis) from the ative IGBA file.

\{Status codes\}-lnitiates the dialog in figure 15. for selecting samples containing specific status codes

\{Additional information\}-Iritiates the dialog in figure 1 fo for selecting samples with specified information tags from the active !GBA file

\{Clear finds\}-Clears the current selection criteria (and removes the $\checkmark$ from beside the corresponding jtems abovel. Any subsequent operations (for example, exporting dalas will be executed on the whole active IGBA file. 


\section{Display> menu}

\{Bibliographic data\}-Reproduces the function of the [book] icon on the right of figure 5 . namely brings up the bibliographic data for the current sample record (as in fig. 6).

\{Next matching sample\}-Reproduces the function of the [right arrow icon on the right of figure 5 , namely searches for the next sample record sequentially in the active IGBA file that matches the current selection criteria (that is, those with $\downarrow$ against them in $<$ Find $>$ menu).

Sample location\}-Reproduces the function of the [globe icon on the right of figure 5, namely brings up a world map showing the location of the currently selected sample with a crosshair (as in fig. $7)$.

[GBA ASCII data\}-Shows the original IGBA coded data-fomat for the currently displayed record, as in figurc 8 .

\section{Acknowledgments}

We thank Felex Chayes and Je Fricado for comments on earlier ilrafts of this report.

\section{References}

Chayes, F., 1982. The rock intiomation system RKNFSYS: Camegie Institution of Washington Yearbook, v. 81, p. 315-316

1983. A Fortran decoder and efaluator for use at operation time: Computers and Geosciences. v.9. p. 537-549

1987. Project 163: Design and generation of a world data hase for igneous petrology, in Skinner. B.J.. ed. Geological correlationScientific achicvements 1983-1987: Paris. Unesco. Special lssue for International Ger]ogical Cortelation Progremme, p. 57-58.

1990. Lioks on the prechistory and carly histnry of digitized data hases and related information systems in igneous petrology: Episodes. v. 13, m. I. p. $1 \mathrm{x}-21$.

1991. IgbaHyp-A Hypercard stack to facilitate proofing of contributions to ICBBADAT, a large and complexly structured datahase impublished reporti
Le Maitre, R.W., 1982, Numerical petrology: Elscvier, Deselopments in Petrology, v. 8, $281 \mathrm{p}$.

NBS (National Bureau of Standards), 1990, Countries, dependencies, areas of special sovereignty and their principal administrative divisions: U.S. Department of Commeree, National Institute of Standards and Technulogy. Federal Information Processing Standard: (FIPS), publication no. 10-3, reference no. NIST-772 (latest revision October 3, 1990).

Rock, N.M.S., 1991, Progress in 1988-1990 with computer applications to the "hard rock" arena-geochemistry, minetalogy, petrology and volcanology: Computers and Genseiences (in press).

Rock, N.M.S.. Shellabear, J.N., Wheatley, M.R., Poulinet, R., and Groves, F.I. 1990, Microcomputers in mineral exploration-a data base for modelling gold depusits in the Yitgarn Block of Western Australia, in Hanlcy. J.T. and Merriam, D.F. eds. Microcomputer applications in Goology, 1I: Pergamon. Compulers in Geology series. พ. 6, p. $199-222$.

Wheatley, M.R, and Rock, N.M.S. 1988, SPIDER: A Macintosh program to grenerate normalized multi-element "spidergrams:" American Mineralogist, v. 73, p. 919-921.

1989. Six dala base management systerns for the Macintosh: Geobyte. พ. 4, ก0. 6, p. 49-56.

Dr. Michael Wheatley was born in Australia and educared at Bristol. Oxford, and London Universitits. He obtained his doctorate after studying applications of gerchemistry in mineral exploration and enivonmenal science. Since 1986, he has worked at the Western Australian Regional Computing Centre, where he is currently Senior Analvst-Programmer, specializing in scientific applications on the Macintosh.

Associate Professor Nicholas Rock was horn in the UK and educated at Cambridge University. After 10 years norking as a field mapper and petrologist with the British Geolopical Surver, including 2 vears secondment in Indonevia, he joined the Unversity of Western Australia. in 1986, as lecturer in geological computing and data analysis. He is currently Deputy Director of the Key Centre in Strategit Mineral Deposits and a recent Head of the Geology Department. He is also Secretary of the IUGS Subcommission on Data Bases for Petrology and Australian representative for both ICCP Project 239 and the Oedan Drilling Program lnformation Handing Panel. Fax: Australia 09-380-1053; e-mat: $N$ ROCK(a fonel.couwa.oz.au. 